(C) Inra/Elsevier, Paris

Original article

\title{
Effects of three fungal pathogens on water relations, chlorophyll fluorescence and growth of Quercus suber L.
}

\author{
Jordi Luque ${ }^{a}$, Moshe Cohen ${ }^{b}$, Robert Savéb ${ }^{\text {, Carmen Biel }}{ }^{b}$, Isabel F. Álvarez ${ }^{a^{*}}$ \\ a Departament de Patologia Vegetal \\ ${ }^{b}$ Departament de Tecnologia Hortícola, Institut de Recerca i Tecnologia Agroalimentàries (IRTA), Centre de Cabrils, \\ Ctra de Cabrils s/n, 08348 Cabrils, Barcelona, Spain
}

(Received 22 September 1997; revised 4 November 1997; accepted 11 March 1998)

\begin{abstract}
Some physiological and growth parameters were studied in cork oak plants inoculated with three pathogenic fungi (Botryosphaeria stevensii, Hypoxylon mediterraneum and Phytophthora cinnamomi) in order to understand the effects of the fungal infection. All inoculated fungi induced the reduction of daily stem growth, stomatal conductance, air-leaf temperature and photochemical efficiency. The more aggressive pathogens, B. stevensii and $P$. cinnamomi, induced the sharpest decline in all growth and physiological parameters. A sudden decline of all variables was caused by $B$. stevensii within 6 days after inoculation, followed by a temporary increase in maximum daily shrinkage coinciding with wilting of the plants. The plants inoculated with $P$. cinnamomi underwent a more gradual decrease in all parameters, whereas $H$. mediterraneum induced a slight but still significant reduction only in stem growth and shrinkage. Linear variable displacement transducers (LVDT) proved to be a suitable tool to measure some effects of the pathogenesis. (@ Inra/Elsevier, Paris.)
\end{abstract}

Botryosphaeria stevensii / Hypoxylon mediterraneum / Phytophthora cinnamomi / pathogenic effect / hydric stress / LVDT

Abbreviations: DE: daily evolution; $g_{\mathrm{s}}$ : stomatal conductance; $F_{\mathrm{v}} / F_{\mathrm{m}}$ : maximum photochemical efficiency; LVDT: linear variable displacement transducer; MDS: maximum daily shrinkage; TD: air-leaf temperature difference.

Résumé - Effets de trois pathogènes fongiques sur les relations hydriques, la fluorescence de la chlorophylle et la croissance de Quercus suber L. Les effets liés à l'infection par trois champignons pathogènes (Botryosphaeria stevensii, Hypoxylon mediterraneum et Phytophthora cinnamomi) sur des plantes de chêne-liège ont été étudiés à partir des paramètres physiologiques et de la croissance. La réduction de la croissance journalière de la tige, la conductance stomatique, l'écart entre la température ambiante et celle de la feuille ainsi que l'efficience photochimique, ont fourni une réponse similaire pour tous les pathogènes en liaison avec leur virulence. $C$ 'est en réponse aux deux plus agressifs, $B$. stevensii et $P$. cinnamomi, que l'on a enregistré les plus fortes réductions de croissance et des paramètres physiologiques. Une chute rapide des valeurs de tous ces paramètres causée par $B$. stevensii a été enregistrée durant les $6 \mathrm{j}$ suivant l'inoculation, accompagnée d'une augmentation des amplitudes de contractions maximales journalières (7-14 j après inoculation) au moment où les plantes commencent à dépérir. Les effets sur l'ensemble des paramètres étaient moins marqués pour les plantes inoculés avec $P$. cinnamomi. Enfin pour Hypoxylon mediterraneum, une réduction plus faible mais toujours significative, a été observée uniquement pour la croissance et pour les amplitudes de contractions des tiges. Les capteurs de déplacement linéaire (LVDT) ont démontré leur efficacité en tant qu'outil pour mesurer certains effets de la pathogènéité. (@) Inra/Elsevier, Paris.)

Botryosphaeria stevensii / Hypoxylon mediterraneum / Phytophthora cinnamomi / effet pathogène / stress hydrique / capteur LVDT

\footnotetext{
* Correspondence and reprints
}

isabel@cabrils.irta.es 


\section{INTRODUCTION}

A substantial increase in cork oak (Quercus suber L.) mortality has been detected since the 1930s in the Mediterranean region [21, 23, 30]. Although its exact causes are still unknown, this increased mortality has been associated with the decline that affects other Quercus species in Europe $[10,16]$. Botryosphaeria stevensii Shoemaker, Hypoxylon mediterraneum (de Not) Ces et de Not and Phytophthora cinnamomi Rands are three frequent decline-associated fungi in the Mediterranean cork oak forests. B. stevensii has an important incidence in the northeast of Spain where it causes dieback and trunk canker in trees harvested for cork [20]. H. mediterraneum is a known pathogen of $Q$. suber $[21,30]$ and other species of Quercus $[6,19,26$, 30]. Host susceptibility to $H$. mediterraneum increases when the tree suffers from water stress $[31,32]$. $P$. cinnamomi, the causal agent of 'ink disease' of many forest species, has been recently associated with the oak decline in the southwest of the Iberian Peninsula [6].

The purpose of this work was to monitor the effects induced by the above decline-associated pathogens on some physiological aspects and growth of $Q$. suber plants. We recorded stem diameter growth, water relations and the photochemical efficiency of inoculated plants in order to relate these parameters to the pathogenesis of each fungus.

\section{MATERIALS AND METHODS}

\subsection{Plant material}

Five months before setting up the experiment 121 year-old plants of $Q$. suber ranging from 40 to $60 \mathrm{~cm}$ in height and 4 to $6 \mathrm{~mm}$ in diameter, measured at $20 \mathrm{~cm}$ height, were transplanted from $750 \mathrm{~mL}$ containers into 5$\mathrm{L}$ pots filled with a sterilized peat:vermiculite mixture (1:1, v:v; final $\mathrm{pH} 5.0)$. The substrate was amended with Osmocote Plus ${ }^{\circledR}$ (Grace-Sierra Spain, Tarragona, Spain) at a dose of $2.5 \mathrm{~g} \mathrm{~L}^{-1}$. The plants were maintained in a greenhouse and irrigated twice a week to substrate capacity throughout the experimental period. Air temperature inside the greenhouse ranged from 15 to $35^{\circ} \mathrm{C}$ during the assay, and was an average $5{ }^{\circ} \mathrm{C}$ higher than the exterior value.

\subsection{Fungal strains}

Three fungal strains isolated from $Q$. suber were used: B. stevensii (Vallgorguina, Barcelona, Spain; isol 24 January 1992); H. mediterraneum (La Bisbal, Girona,
Spain; isol 5 October 1992); and $P$. cinnamomi (St. Sadurní de l'Heura, Girona, Spain; isol 19 June 1995). All strains were maintained in potato dextrose agar (PDA) plugs in tubes with sterile distilled water at $4{ }^{\circ} \mathrm{C}$ until use. The strains were recovered by plating a small piece of the mycelium in PDA and incubating it at $25^{\circ} \mathrm{C}$ for 4 days.

\subsection{Inoculations}

The plants were inoculated on 27 March 1996. A superficial wound, $1.5 \mathrm{~cm}$ long, was made on the stem of every plant with a sterile blade at 15 to $20 \mathrm{~cm}$ above the ground level. A mycelial plug (4 $\mathrm{mm}$ in diameter) from an actively growing colony was placed on the wound with the mycelial surface in contact with the stem tissues. The wounds were sealed with Parafilm ${ }^{\circledR}$ (American National Can, Greenwich, CT, USA). Groups of three plants were inoculated with each fungus, and controls consisted of three additional plants treated in a similar way but with plugs of sterile PDA. At the end of the experiment, isolations were made from all the plants at the point of inoculation and $3 \mathrm{~cm}$ above it by plating in PDA wood pieces disinfected with ethanol $70^{\circ}$ and incubating them at $25^{\circ} \mathrm{C}$ for fungal identification.

\subsection{Monitoring}

The microvariations of stem diameter throughout the experimental period, 28 March-22 May, were measured with a set of linear variable displacement transducers (LVDT: model DF, range $\pm 2.5 \mathrm{~mm}$, accuracy $\pm 10 \mu \mathrm{m}$, from Solartron [Solartron Metrology, Bogno Regis, UK]). One sensor was attached to each stem $15 \mathrm{~cm}$ above the inoculation point with a special holder made of Invar material. The LVDT outputs were recorded with a datalogger (model CR10 with a multiplexer AM416 from Campbell [Campbell Scientific Ltd., Logan, UT, USA) every $30 \mathrm{~s}$ and averaged every $20 \mathrm{~min}$.

Stomatal conductance $\left(g_{s}\right)$ and both air and leaf temperatures were measured with a steady-state porometer (model LI-1600, from Li-Cor Inc., Lincoln, NE, USA). Chlorophyll fluorescence induction was followed for $4 \mathrm{~s}$ from the irradiated leaf surface with a Plant Efficiency Analyzer (PEA: Hansatech Instruments, King's Lynn, UK). Exciting red light at $1500 \mu \mathrm{mol} \cdot \mathrm{m}^{-2} \cdot \mathrm{s}^{-1}$ was routinely used and leaves were dark-adapted for $20 \mathrm{~min}$ before measurements.

Porometric and chlorophyll fluorescence measurements were taken at midday, on two fully developed, symptomless, randomly selected leaves of the current 
year of all inoculated and control plants. For the first 3 weeks, porometry and fluorescence readings were taken at midday approximately twice a week. Thereafter, measurements were made once a week. Visually appreciable changes in the vigour of the plants were annotated twice a week throughout the experimental period.

\subsection{Data analyses}

The raw data from the LVDT sensors were corrected to the same initial zero value. Three parameters were studied [7]: i) total increase of the stem diameter, ii) maximum daily shrinkage (MDS) of the stem diameter (difference between the maximum and minimum of each daily curve) and its relative values against control (relative MDS), and iii) daily evolution (DE), increasing or decreasing of the stem diameter measured at 0600 hours of two consecutive days. Air minus canopy temperature differences (TD) were obtained from leaf and cuvette porometer readings [25]. The ratio $F_{\mathrm{v}} / F_{\mathrm{m}}$ (maximum PS II photochemical efficiency) is a sensitive indicator of photoinhibition and other stresses, including altered responses in infected plants $[1,12,24]$.

All data were analyzed using the SYSTAT statistical package [29]. Autocorrelation analyses were made with MDS and DE values of each inoculation treatment to check for the time independence of the measurements taken during the assay. After that, one-way analysis of variance (ANOVA) was performed (considering as replicates the daily averages) and means were compared against control by Dunnett's test. Data obtained with the porometer and the PEA were analyzed using one-way ANOVA and differences from control means in each reading date were detected by Dunnett's test.

\section{RESULTS}

The presence of the pathogens in the inoculated plants was confirmed by positive re-isolations at the end of the experimental period. Tissue necroses, variable in size, were observed in all inoculated plants. The wounds of the control plants healed successfully and no fungus was isolated from them. The plants inoculated with $H$. mediterraneum looked similar to control plants and produced new leaves throughout the experimental period. However, superficial bark cankers of 2 to $3 \mathrm{~mm}$ were detectable around the point of inoculation in the 5 th week after inoculation.

The plants inoculated with $B$. stevensii showed clear symptoms of infection after only 1 week. A gradual wilting of the leaves led to the death of two of the inoculated plants in 13 days. The surviving $B$. stevensii-inoculated plant recovered after 25 days for unknown reasons that will require further research, but for the purpose of the study reported here the data were excluded. All plants inoculated with $B$. stevensii developed cankers of 4 to $10 \mathrm{~cm}$ around the point of inoculation in 3 weeks. Cankers were characterised by darkening and depression of vascular and bark tissues. The formation of pycnidia on the bark was detected 5 weeks after inoculation.

One plant inoculated with $P$. cinnamomi wilted 3 days before the experiment ended. Its death was preceded the previous week by gradual chlorosis of the old leaves. All plants inoculated with $P$. cinnamomi showed canker formation in 22 days, followed by epicormic branching.

The mean diameter increase for each treatment during the assay is shown in figure 1 . The mean overall growth was $3.49 \mathrm{~mm}$ for control plants, $2.83 \mathrm{~mm}$ for plants inoculated with $H$. mediterraneum, $0.79 \mathrm{~mm}$ for $P$. cinnamo$m i$ inoculated plants, and $-1.04 \mathrm{~mm}$ for the plants killed by $B$. stevensii. Only the last group showed a differential trend which can be separated in three phases: a growth period of 5 days following inoculation, a sharp decrease of stem diameter together with larger MDS values, coinciding with the death of plants 13 days after inoculation, and a slow decline of stem diameter with reduced MDS values.

Mean relative MDS and DE data are shown in figure 2. Daily MDS values for all treatments ranged from 0 to $180 \mu \mathrm{m}$, with minimum values recorded on cloudy or rainy days, when stomatal conductance was low. The highest values usually corresponded to control plants.

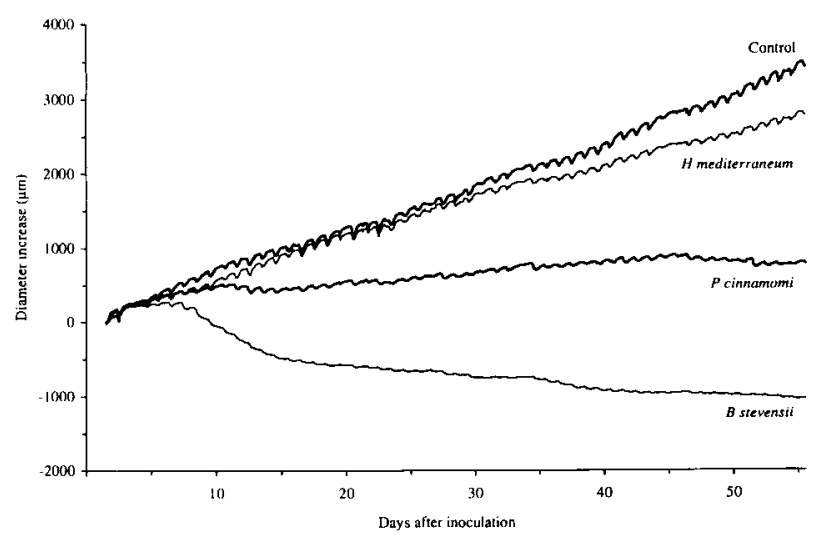

Figure 1. Time course of mean stem diameter of Quercus suber plants inoculated with Botryosphaeria stevensii $(n=2)$, Hypoxylon mediterraneum $(n=3)$ and Phytophthora cinnamo$m i(n=3)$. 
A

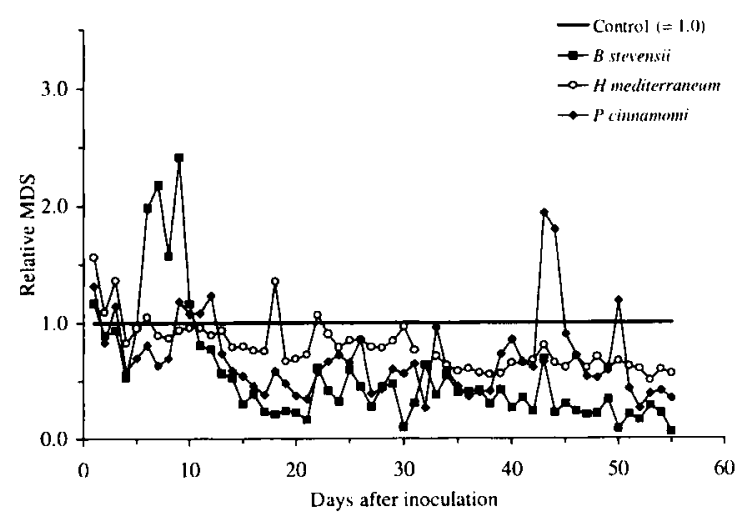

B

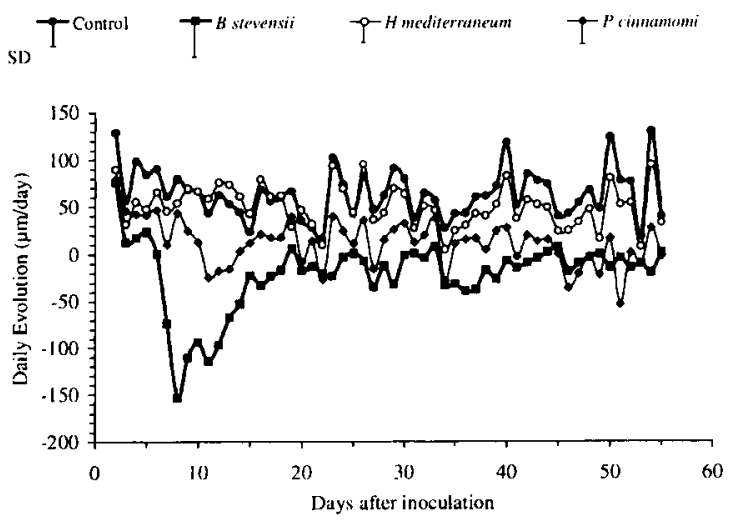

Figure 2. (A) Mean maximum daily shrinkage (MDS), and (B) daily evolution (DE) of stem diameter in Quercus suber plants inoculated with Botryosphaeria stevensii $(n=2)$, Hypoxylon mediterraneum $(n=3)$ and Phytophthora cinnamomi $(n=3)$. Vertical bars associated with the legend symbols indicate the pooled standard deviation of the means.

Relative MDS values for plants inoculated with $B$. stevensii were approximately two times greater than control 6 days after inoculation, and reached 2.5 times after 9 days (figure $2 A$ ). DE values for control plants ranged from 16 to $129 \mu \mathrm{m} /$ day (d) (figure $2 B$ ). The plants inoculated with $H$. mediterraneum had a positive DE range ( 4 to $95 \mu \mathrm{m}$ $\mathrm{d}^{-1}$ ), sometimes larger than control plants ( 8 to 19 days after inoculation). The plants inoculated with $B$. stevensii displayed DE varying from -154 to $75 \mu \mathrm{m} \mathrm{d}^{-1}$. Negative values were obtained 6 days after inoculation. DE values for $P$. cinnamomi-inoculated plants ranged from -53 to $79 \mu \mathrm{m} \mathrm{d}^{-1}$, with occasional periods of negative data following inoculation and the death of one plant.
Table I. Maximum daily shrinkage and daily evolution of the stem diameter measured in Quercus suber plants inoculated with Botryosphaeria stevensii, Hypoxylon mediterraneum and Phytophthora cinnamomi.

\begin{tabular}{lcc}
\hline Treatment & $\begin{array}{c}\text { Maximum daily } \\
\text { shrinkage }(\mu \mathrm{m})\end{array}$ & $\begin{array}{c}\text { Daily evolution } \\
\left(\mu \mathrm{m} \mathrm{d}^{-1}\right)\end{array}$ \\
\hline Control & 69.2 & 63.7 \\
Botryosphaeria stevensii & $31.4^{* *}$ & $-22.0^{* *}$ \\
Hypoxylon mediterraneum & $53.0^{* *}$ & $50.2^{*}$ \\
Phytophthora cinnamomi & $43.8^{* *}$ & $11.6^{* *}$ \\
\hline
\end{tabular}

Average values from 55 daily mean values of three inoculated plants per treatment (except $B$. stevensii; $n=2$ ). Significance of Dunnett's test: $* P<0.05$; $* * P 0.01$. Original data were log-transformed.

The results from MDS and DE data analyses are shown in table I. Autocorrelation coefficients were not statistically significant in any case. Thus, independence of the measures within the time series of each treatment was presumed and data were then analyzed using oneway ANOVA. The MDS and DE means for the control plants were $69.2 \mu \mathrm{m}$ and $63.7 \mu \mathrm{m} \mathrm{d}^{-1}$, significantly greater than inoculated plants. The lowest MDS and DE values corresponded to the plants infected by $B$. stevensii $\left(31.4 \mu \mathrm{m}\right.$ and $-22.0 \mu \mathrm{m} \mathrm{d}^{-1}$, respectively) followed by $P$. cinnamomi- and $H$. mediterraneum-infected plants, respectively (table $I$ ).

To analyze more precisely the MDS and DE data of the plants infected by $B$. stevensii three periods were defined: $0-6,7-14$ and 15-56 days after inoculation which related, respectively, to absence of symptoms, appearance of wilting and death of the plants (table II). Mean MDS values for the plants inoculated with $B$ stevensii ranged from 21.6 to $77.3 \mu \mathrm{m}$, with significantly different values only in the last period. The control plants gradually increased their MDS means from 41.4 to 74.0 $\mu \mathrm{m}$. Mean DE values for control plants decreased from 91.4 to $61.1 \mu \mathrm{m} \mathrm{d}^{-1}$, while the DE means for $B$. stevensiiinfected plants were always lower and significantly different. Negative values were obtained 7 days after inoculation and thereafter.

The results from air-leaf temperature, stomatal conductance and chlorophyll fluorescence measurements are shown in figure 3. Mean TD values for control plants and those inoculated with $H$. mediterraneum were always positive, ranging from 0.1 to $0.9^{\circ} \mathrm{C}$. Both groups behaved similarly and no significant differences were detected during the experiment. Plants inoculated with $B$. stevensii experienced a sudden and significant decrease $(P<0.05)$ in TD 5 days after inoculation. Average TD values for the plants inoculated with $P$. cinnamomi ranged from -1.1 to 
Table II. Maximum daily shrinkage and daily evolution of the stem diameter measured in Quercus suber plants inoculated with Botryosphaeria stevensii.

\begin{tabular}{|c|c|c|c|c|c|c|}
\hline \multirow[t]{2}{*}{ Treatment } & \multicolumn{3}{|c|}{ Maximum daily shrinkage $(\mu \mathrm{m})$} & \multicolumn{3}{|c|}{ Daily evolution $\left(\mu \mathrm{m} \mathrm{d} \mathrm{d}^{-1}\right)$} \\
\hline & \multicolumn{3}{|c|}{ Days after inoculation } & \multicolumn{3}{|c|}{ Days after inoculation } \\
\hline Control & 41.4 & 61.7 & 74.0 & 91.4 & 59.5 & 61.1 \\
\hline Botryosphaeria stevensii & 40.1 & 77.3 & $21.6 * *$ & $25.8 * *$ & $-95.3 * *$ & $-13.6 * *$ \\
\hline
\end{tabular}

Average values from daily means corresponding to three control plants and two infected with $B$. stevensii. Significance of Dunnett's test: ${ }^{*} P<0.01$. Original data were log-transformed. Symptomatology: a: absence of symptoms; b: progressive wilting; $c$ : dead plants. Canker, pycnidia and epicormic branching are visible.

$0.0^{\circ} \mathrm{C}$, which were significantly different $(P<0.05)$ from the control on the 5th day and thereafter.

Mean $g_{5}$ rates of control plants ranged from 216 to $375 \mathrm{mmol} \cdot \mathrm{m}^{-2} \cdot \mathrm{s}^{-1}$ (figure 3). Plants inoculated with $H$. mediterraneum behaved similarly to control plants with values ranging from 179 to $390 \mathrm{mmol} \cdot \mathrm{m}^{-2} \cdot \mathrm{s}^{-1}$. Only the values at 15,29 and 41 days after inoculation were significantly different from control. Plants infected with $B$. stevensii showed a sharp decrease (down to $21 \mathrm{mmol} \cdot \mathrm{m}^{-2} \cdot \mathrm{s}^{-1}$ ) in only 5 days, well before death occurred. Plants infected with $P$. cinnamomi always showed significantly $(P<0.05)$ lower values than those of control from 5 days on (range: 19 to $120 \mathrm{mmol} \cdot \mathrm{m}^{-2} \cdot \mathrm{s}^{-1}$ ). The negative trend was stabilised after 3 weeks and the average of the $g_{\mathrm{s}}$ rates for the remaining measurement periods represented the $11 \%$ of the mean control value.

Control plants and those inoculated with $H$. mediterraneum had similar values of $F_{\mathrm{v}} / F_{\mathrm{m}}$ throughout the experimental period, ranging from 0.77 to 0.83 . Plants inoculated with $B$. stevensii underwent a sharp and significant decrease in $F_{\mathrm{v}} / F_{\mathrm{m}}$ (to 0.07$)$ in 13 days $(P<0.05)$, whereas $P$. cinnamomi-inoculated plants displayed a gradual decline, reaching significant differences from control 30 days after inoculation.

\section{DISCUSSION}

Control plants grew adequately during the assay. This was shown by the daily evolution of their stem diameters and the chlorophyll fluorescence, two integrative variables not related to rapid environmental changes [18, 24].

The three pathogens induced effects on the plants at different time intervals. Thus, a negative influence in overall stem diameter growth and DE can be observed in all infected plants (figure 1 , tables $I$ and $I$ ). The minimum stem diameter growth was observed in plants infect- ed by $B$. stevensii, followed by $P$. cinnamomi and $H$. mediterraneum. External appearance of the plants inoculated with $H$. mediterraneum was similar to control plants.

Mean MDS values of the plants infected with $B$. stevensii were lower than control plants, except for the period following 7 to 14 days after inoculation (table $I$ ). We speculate that these higher MDS values were probably due to the occlusion of vessels caused by the pathogen and an increased use of the plant water reserves. Lowest MDS values were induced by $B$. stevensii, followed by $P$. cinnamomi. Plants infected by $H$. mediterraneum had slight but still significant reductions in both MDS and DE.

The stem diameter time course of the inoculated $Q$. suber plants was similar to Cistus salviifolius L. also inoculated with either $B$. stevensii or $H$. mediterraneum [7]. Similar responses detected by LVDT sensors were found in plants of several fruit tree species submitted to water stress $[14,15]$.

The results obtained in air-leaf temperature difference, stomatal conductance and photochemical efficiency showed the global reduction of these parameters in all infected plants (figure 3).

Sharp decreases in all measured variables of the plants inoculated with $B$. stevensii occurred before any symptom was visually noticeable. Differences between $B$. stevensii-infected and control plants were detected earlier by the DE parameter than by the MDS.

$P$. cinnamomi induced significant reductions in TD $(200 \%)$ and $g_{\mathrm{s}}(89 \%)$ when compared to control values. Dawson and Weste [8] detected similar decreases (about $75 \%)$ in stomatal conductance and transpiration of Eucalyptus sieberi LAS Johnson infected with $P$. cinnamomi. The decrease in $F_{\mathrm{v}} / F_{\mathrm{m}}$ was only significant after 30 days of inoculation. Epron and Dreyer [11] and Méthy et al. [22] observed comparable reductions of $F_{\mathrm{v}} / F_{\mathrm{m}}$ in 

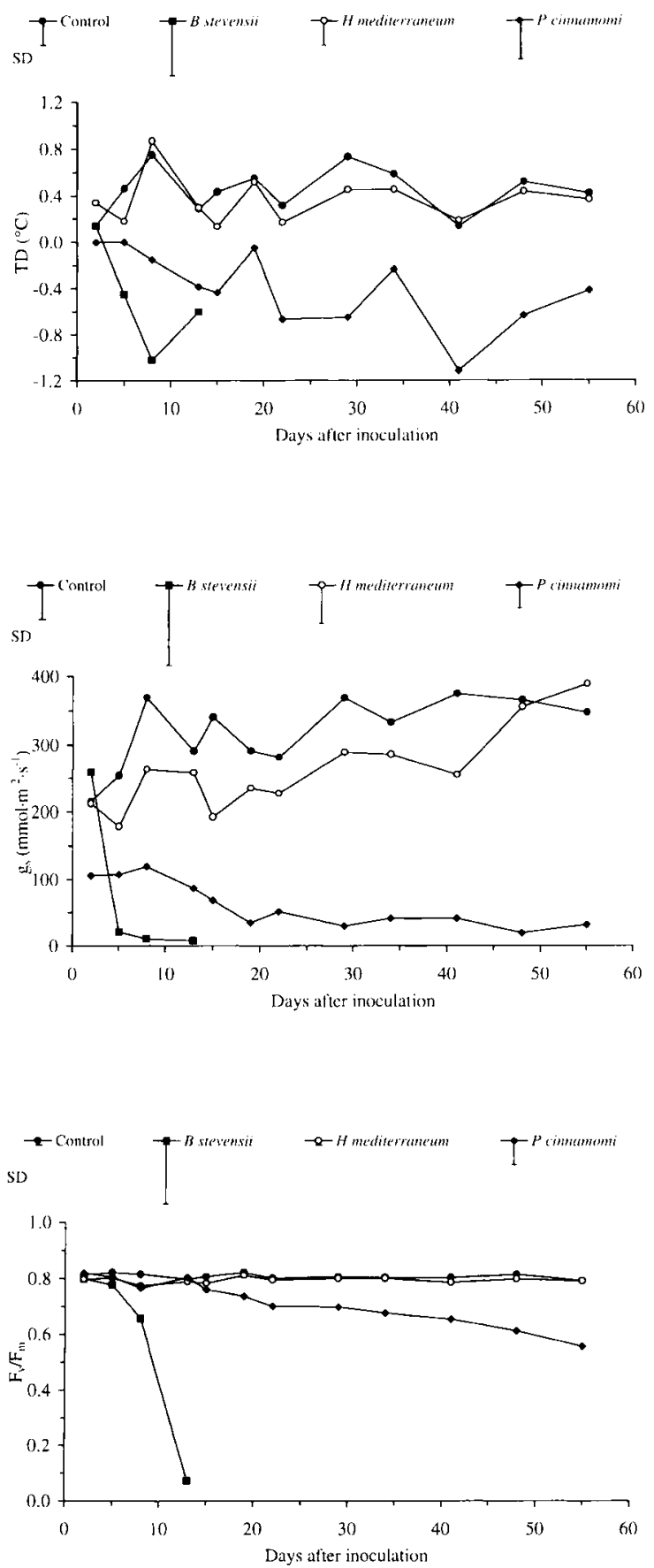

Figure 3. Time course of air-leaf temperature differences (TD), stomatal conductance $\left(g_{*}\right)$, and photochemical efficiency $\left(F_{\mathrm{v}} / F_{\mathrm{m}}\right)$ of Quercus suber plants inoculated with Botryosphaeria stevensii $(n=2)$, Hypoxylon mediterraneum $(n=3)$ and Phytophthora cinnamomi $(n=3)$. Vertical bars associated with the legend symbols indicate the pooled standard deviation of the means.
Quercus ilex L., Q. petraea (Matt.) Liebl. and Q. pubescens Willd. plants submitted to severe drought stress. The effects of pathogens on plants show a pattern similar to drought stress, since infection induces a reduction of water flux from roots to leaves $[3,27]$. The occurrence of hydric stress due to pathogens has been reviewed by several authors $[2,9,13,17]$

The inoculation of $H$. mediterraneum induced decreases in TD $(17 \%), g_{\mathrm{s}}(12 \%)$ and $F_{\mathrm{v}} / F_{\mathrm{m}}(2 \%)$. Several workers $[6,26,30,31]$ established that the pathogenic effects of $H$. mediterraneum on several species of Quercus only appeared when the vigour of the host was affected (usually by water stress). However, our results indicate that even in the absence of water stress, the LVDT sensors detected a significant pathogenic effect of $H$. mediterraneum as indicated by the MDS and DE values (table I). Moreover, it can be assumed that fungal development within the plants induced decreasing values in TD, $g_{\mathrm{s}}$ and $F_{\mathrm{v}} / F_{\mathrm{m}}$, although the differences were insignificant when compared to control. On the other hand, Vannini and Valentini [32] detected an average loss of $33 \%$ in hydraulic conductivity of stems of Quercus cerris $\mathrm{L}$. when inoculated with $H$. mediterraneum and the plants were grown without hydric restrictions. These results indicate that the pathogenic effect of $H$. mediterraneum on the host can be considerable even in the absence of drought conditions. Certainly, additional experiments are needed involving young/adult plants and stress/non-stress conditions to elucidate more accurately the pathogenic effects of Hypoxylon species. Continuous recording of stem diameter variations could be a beneficial methodology in future research.

Although the exact mechanisms involved are still unknown, the experiments described in this work demonstrate a clear negative effect of several pathogenic fungi on water transport, photosynthetic activity and growth of infected cork oak plants. These symptoms resemble those produced by severe water stress in non-infected plants $[18,28]$. Brasier [4] and Wargo [33] considered that $P$. cinnamomi predisposes the adult plants of $Q$. ilex and $Q$. suber to drought stress rather than the opposite. Dawson and Weste [8] also described typical symptoms of water stress associated with $P$. cinnamomi infection processes.

\section{CONCLUSION}

The infection of cork oak plants with three pathogenic fungi induces a common plant response, characterised by decreases in both daily stem shrinkage and growth, stomatal conductance and air-leaf temperature. Low values of these parameters indicate a disorder in the plant metabolic functioning which reduces hydric and energetic 
resources available for the growth and defense of the infected plants.

Water relations, air-leaf thermal measurements and daily evolution of stem diameter are useful indicators of plant distress during the first infection phases when symptoms are not visually detectable. Long-term effects of fungal infection undetectable by other methods (porometry, fluorescence) can be measured using LVDT sensors.

Acknowledgements: J. Luque was the recipient of a fellowship (FI-PG/94-9.806) provided by the Direcció General de Recerca of the Generalitat de Catalunya.

\section{REFERENCES}

[1] Araus J.L., Hogan K.P., Leaf structure and patterns of photoinhibition in two neotropical palms in clearings and forest understory during the dry season, Am. J. Bot. 81 (1994) 726-738.

[2] Ayres P.G., Water relations of diseased plants, in: Kozlowski T.T. (Ed.), Water Deficits and Plant Growth. V. Water and Plant Disease, Academic Press, London, 1978, pp. $1-60$.

[3] Ayres P.G., Growth responses induced by pathogen and other stresses, in: Mooney H.A., Winner W.E., Pell E.J. (Eds.), Response of Plants to Multiple Stresses, Academic Press, San Diego, 1991, pp. 227-248.

[4] Brasier C.M., Phytophthora cinnamomi as a contributory factor in European oak declines, in: Luisi N., Lerario P., Vannini A. (Eds.), Recent Advances in Studies on Oak Decline, University of Bari (Italy), 1993, pp. 49-57.

[5] Brasier C.M., Robredo F., Ferraz J.F.P., Evidence for Phytophthora cinnamomi involvement in Iberian oak decline, Plant Pathol. 42 (1993) 140-145.

[6] Capretti P., Mugnai L., Disseccamenti di cerro da Hypoxylon mediterraneum (De Not) Mill., Inf. Fitopatol. 37 (1987) 39-41.

[7] Cohen M., Luque J., Álvarez I.F., Use of stem diameter variations for detecting the effects of pathogens on plant water status, Ann. Sci. For. 54 (1997) 463-472.

[8] Dawson P., Weste G., Impact of root infection by Phytophthora cinnamomi on the water relations of two Eucalyptus species that differ in susceptibility, Phytopathology 74 (1984) 486-490.

[9] Duniway J.M., Pathogen-induced changes in host water relations, Phytopathology 63 (1973) 458-466.

[10] EPPO, Oak decline and the status of Ophiostoma spp. on oak in Europe, EPPO Bull. 20 (1990) 405-422.

[11] Epron D., Dreyer E., Stomatal and non stomatal limitation of photosynthesis by leaf water deficits in three oak species: a comparison of gas exchange and chlorophyll a fluorescence data, Ann. Sci. For. 47 (1990) 435-450.

[12] Epron D., Dreyer E., Bréda N., Photosynthesis of oak trees [Quercus petraea (Matt) Liebl] during drought under field conditions: diurnal course of net $\mathrm{CO}_{2}$ assimilation and photochemical efficiency of photosystem II, Plant Cell Environ. 15 (1992) 809-820.

[13] Hall R., Effects of root pathogens on plant water relations, in: Ayres P.G., Boddy L. (Eds.), Water, Fungi and Plants. Symposium of the British Mycological Society, April 1985, Cambridge University Press, Cambridge, 1986, pp. 241-265.

[14] Huguet J.G., Appréciation de l'état hydrique d'une plante à partir des variations micrométriques de la dimension des fruits ou des tiges au cours de la journée, Agronomie 5 (1985) 733-741.

[15] Huguet J.G., Li S.H., Lorendeau J.Y., Pelloux G., Specific micromorphometric reactions of fruit trees to water stress and irrigation scheduling automation, J. Hortic. Sci. 67 (1992) 631-640.

[16] Jacobs K.A., Álvarez I.F., Luque J., Association of soil, site and stand factors with decline of Quercus suber in Catalonia, Spain, in: Luisi N., Lerario P., Vannini A. (Eds.), Recent Advances in Studies on Oak Decline, University of Bari (Italy), 1993, pp. 193-203.

[17] Jones H.G., Movement of liquid water and the effects of fungal infection, in: Ayres P.G., Boddy L. (Eds.), Water, Fungi and Plants. Symposium of the British Mycological Society, April 1985, Cambridge University Press, Cambridge, 1986, pp. 223-239.

[18] Kozlowski T.T., Pallardy S.G., Growth Control in Woody Plants, Academic Press, San Diego, 1997, 641 p.

[19] Luisi N., Manicone R.P., Sicoli G., Lerario P., Pathogenicity tests of fungi associated with oak decline on Quercus spp. seedlings grown at different water regimes, in: Luisi N., Lerario N., Vannini A. (Eds.), Recent Advances in Studies on Oak Decline, University of Bari (Italy), 1993, pp. $85-93$.

[20] Luque J., Girbal J., Dieback of cork oak (Quercus suber) in Catalonia (NE Spain) caused by Botryosphaeria stevensii, Eur. J. For. Pathol. 19 (1989) 7-13.

[21] Malençon G., Marion J., L'Hypoxylon mediterraneum (De Not) Ces et De Not et son comportament épiphytique dans les chênaies nordafricaines, Rev. Mycol. 17 (Suppl. colon 2) (1952) 49-73.

[22] Méthy M., Damesin C., Rambal S., Drought and photosystem II activity in two Mediterranean oaks, Ann. Sci. For. 53 (1996) 255-262.

[23] Natividade J.V., Subericultura, 2nd ed., Ministério da Agricultura, Pescas e Alimentação, Lisbon, 1990, 387 p.

[24] Pearcy R.W., Ehleringer J., Mooney H.A., Rundel P.W., eds., Plant Physiological Ecology. Field Methods and Instrumentation, Chapman and Hall, London, 1989, $457 \mathrm{p}$.

[25] Peñuelas J., Savé R., Marfà O., Serrano L., Remote sensing of infrared signal in strawberries submitted to mild and very mild water stress, Agric. For. Meteor. 58 (1992) 63-77.

[26] Ragazzi A., Dellavalle I., Mesturino L., The oak decline: a new problem in Italy, Eur. J. For. Pathol. 19 (1989) $105-110$. 
[27] Shain L., Stem defense against pathogens, in: Gartner B. (Ed.), Plant Stems. Physiology and Functional Morphology, Academic Press, San Diego, 1995, pp. 383-406.

[28] Smith J.A.C., Griffiths H., eds., Water Deficits. Plant Responses from Cell to Community, Bios Scientific Publishers, Oxford, 1993, $345 \mathrm{p}$.

[29] SYSTAT, SYSTAT for Windows: Statistics, Version 5 Edition, SYSTAT Inc., Evanston, IL, USA, 1992, 750 p.

[30] Torres Juan J., El Hypoxylon mediterraneum (De Not) Mill y su comportamiento en los encinares y alcornocales andaluces, Bol. Serv. Plagas 11 (1985) 185-191.
[31] Vannini A., Scarascia Mugnozza G., Water stress: a predisposing factor in the pathogenesis of Hypoxylon mediterraneum on Quercus cerris, Eur. J. For. Pathol. 21 (1991) 193-201.

[32] Vannini A., Valentini R., Influence of water relations on Quercus cerris-Hypoxylon mediterraneum interaction: a model of drought-induced susceptibility to a weakness parasite, Tree Physiol. 14 (1994) 129-139.

[33] Wargo P.M., Consequences of environmental stress on oak: predisposition to pathogens, Ann. Sci. For. 53 (1996) 359-368. 